\title{
Towards a unified classification of wear
}

\author{
Michael VARENBERG* \\ Department of Mechanical Engineering, Technion - IIT, Haifa 32000, Israel \\ Received: 12 July 2013 / Revised: 03 September 2013 / Accepted: 26 September 2013 \\ (C) The author(s) 2013. This article is published with open access at Springerlink.com
}

\begin{abstract}
Since the beginning of the systematic study of wear, many classification schemes have been devised. However, though covering the whole field in sum, they stay only loosely connected to each other and do not build a complete general picture. To this end, here we try to combine and integrate existing approaches into a general simple scheme unifying known wear types into a consistent system. The suggested scheme is based on three classifying criterions answering the questions "why", "how" and "where" and defining a 3-D space filled with the known wear types. The system can be used in teaching to introduce students to such complex phenomena as wear and also in engineering practice to guide wear mitigation initiatives.
\end{abstract}

Keywords: relative motion; energy dissipation; surface disturbance; surface state; surface damage

\section{Introduction}

The origin of analysis lays in identifying similarities in a diversity of things and processes we deal with and arranging entities into classes of similar items. Without first bringing order into any field we work in, it is nearly impossible to understand anything or make any statement about it. It is for this reason that classification is one of the most important methods of science [1].

Though first recorded observations of wear date back to the $1^{\text {st }}$ century BCE [2], apart from the work of Leonardo da Vinci (circa 1493) that remained lost in libraries until 1967 [3], the systematic studies of wear have started far more recently [4,5]. It was the requirement for increased accuracy and smaller clearances needed for successful operation of early twentieth-century machinery that have led to the growing interest in wear studies, which were further supported by the advent of modern imaging techniques having an adequate resolution [6, 7]. Since then, many classification schemes have been devised, partly due to the accumulation of knowledge and partly due to the complexity of wear processes leaving much room

* Corresponding author: Michael VARENBERG.

E-mail: michaelv@technion.ac.il for various interpretations.

Classification suggested by Siebel in 1938 relied on the type of relative motion as a classifying criterion [4]. The distinguished classes of wear were related to (1) dry sliding, (2) lubricated sliding, (3) dry rolling, (4) lubricated rolling, (5) oscillating, (6) solid particles motion, and (7) fluids motion. Classification suggested by Archard and Hirst in 1956 relied on the scale of surface damage as a classifying criterion [8]. The distinguished classes of wear were (1) mild wear and (2) severe wear related to localization of surface damage within the layers of different chemical composition, outer protective and inner bulk ones, respectively. Classification suggested by Burwell in 1957 relied on the type of wear mechanism as a classifying criterion [9]. The distinguished classes of wear were related to (1) adhesive, (2) abrasive, (3) corrosive, and (4) surface fatigue mechanisms, and (5) other minor wear types, such as erosion and impact chipping. Classification suggested by Kostetskii et al. in 1976 relied on the reliability of surface performance and the nature of interaction processes as two classifying criterions $[10,11]$ The distinguished classes of wear were (1) acceptable wear consisting of (a) normal mechanochemical oxidative, (b) normal mechanochemical non-oxidative, and (c) mechanochemical form of abrasive wear, and 
(2) unacceptable damage consisting of (a) seizure, (b) fretting damage, (c) mechanical form of abrasive wear, (d) rolling fatigue (pitting), and (e) other forms of damage, such as corrosion, erosion, cavitation, and crushing. Classification suggested by Czichos in 1978 integrated some of the previous approaches and relied on the type of relative motion, the interacting elements, and the dominant wear mechanism as three classifying criterions [12]. The distinguished classes of wear were (1) sliding wear, (2) rolling wear, (3) impact wear, (4) fretting wear, (5) cavitation wear, and (6) fluid erosion ordered into a table of six rows representing the relative motion types grouped by the interacting elements and four columns representing the main wear mechanisms able to act in various combinations within each of the six classes of wear. Classification suggested by Lim and Ashby in 1987 relied on the mechanism of surface interaction as a classifying criterion [13]. The distinguished classes of wear were (1) seizure, (2) melt-dominated wear, (3) oxidationdominated wear, and (4) plasticity-dominated wear, while the last two groups were additionally subdivided into (a) mild and (b) severe wear subclasses.

To the best of my judgement, these schemes make a list of the most important approaches to classification of wear. However, though covering the whole field in sum, they stay only loosely connected to each other and do not build a complete general picture. In trying to introduce students to such complex phenomena as wear when teaching undergraduate course on tribology, it became clear to me that there is a need to devise a basic classification, which may present the state of the art before entering microscopic or even nanoscale origins of wear. To this end, the goal of this paper is to review, combine and integrate the existing approaches into a general scheme unifying known wear types into a consistent system. The target audience is scholars who study, teach or start practicing solving the wear-related problems.

\section{Definitions}

Systematizing the wear classification schemes developed so far, we can normalize the used classifying criterions according to Table 1. Presented in this way, they allow us to see that there are only three independent ones: (1) relative motion, which also
Table 1 Normalized classifying criterions used in key classification schemes.

\begin{tabular}{lll}
\hline Year & \multicolumn{1}{c}{ Author(s) } & \multicolumn{1}{c}{ Classifying criterion(s) } \\
\hline 1938 & Siebel & 1. Relative motion \\
1956 & Archard \& Hirst & 1. Damage severity \\
1957 & Burwell & 1. Damage mechanism \\
1976 & Kostetskii et al. & 1. Damage severity \\
& & 2. Damage mechanism \\
1978 & Czichos & 1. Relative motion \\
& & 2. Interacting elements \\
& & 3. Damage mechanism \\
1987 & Lim \& Ashby & 1. Interaction mechanism \\
& & 2. Damage severity \\
\hline
\end{tabular}

determines the interacting elements, (2) mechanism of what happens to the surface, when interaction mechanism refers to the process and damage mechanism refers to the result, and (3) damage severity. It is easy to assume that the generalized classification of wear should also rest on the system of three independent axes. Supported by this assumption and based on previous studies, we will now proceed to the following in an attempt to derive all classifiers from the common source.

Wear is defined as the damage to a solid surface, generally involving progressive loss of material, due to relative motion between that surface and a contacting substance or substances [14]. Based on this simple definition, we can recognise three classifying criterions according to which the system has to be characterized. These are the answers to the following questions: (1) Why does it happen? (2) How does it happen? and (3) Where does it happen? To make the picture complete, it is probably worth adding that the other interrogative words used in gathering information seem not relevant, as the answers are known (who-wear process, what-damages the surface, when-continuously).

\subsection{Why?}

The question "why" determines the reason, which is explicitly specified in the above definition as a relative motion. Clearly, the type of relative motion will serve us as a first classifying criterion.

Analysing relative motion, we can distinguish between the following five types. (1) Fretting, which, according to a less known (but more accurate than 
classic) definition [15], is the relative cyclic motion between two solid bodies, having a non-uniform distribution of local relative displacement at their contact. This type of motion is directly connected to preliminary displacement [16], which always takes place before gross sliding occurs. (2) Sliding, the relative motion in the tangential plane of contact between two solid bodies [14]. To distinguish it from fretting, it is worth adding that sliding is the uniform relative motion, which means that it is possible to neglect the differences in distribution of local relative displacement at the contact zone. (3) Rolling, the relative motion between two non-conforming solid bodies whose surface velocities in the nominal contact location are identical in magnitude, direction, and sense [14]. (4) Impact, the relative cyclic motion between two solid bodies that come in and out of contact. (5) Flow, the relative motion between a solid body and a fluid.

\subsection{How?}

The question "how" illuminates the mechanism, which can also be deduced from the above definition. The surface under consideration interacts with "a contacting substance or substances", which results in external forces exerted on it. Given the presence of relative motion, these forces act through certain distances so mechanical work is performed on the surface, and the latter accumulates energy that has to be dissipated. The amount of energy involved in this process actually determines the form of surface damage [11], allowing us to define the second classifying criterion based on energy dissipation.

Examining the processes of conversion and dissipation of mechanical energy taking place within the topmost surface layers, we can list the following "losses". The energy is expended on generation of structural defects (dislocations, stacking faults, cracks, vacancies, misplacements, stripe patterns, etc.), stored as a result of elastic strains, emitted in the form of phonons (acoustic waves and sound), photons (triboluminescence) and electrons (exo-electrons, Kramer effect), and transformed into heat [17]. Interestingly, all these processes constitute the ultimate origin of friction [17], though not all of them give rise to wear, which may probably explain the well-known inconsistency between, say, the coefficients of friction and the coefficients of wear. Analysing this list, we come to the conclusion that the wear-related energy losses are pooled from (a) generation of defects, leading to internal material changes, and (b) generation of heat, leading to increase in temperature activating interactions with external agents. Both items can be traced further, to let us distinguish between the following four processes to be united under the name of surface disturbance. (1) Storage of defects, which can appear or move to, and pile up at certain characteristic locations. (2) Motion of defects, which can come and leave, passing through a material volume under consideration. (3) Chemical interactions, which consist of reactions with active environmental elements to form secondary surface films. (4) Physical interactions, which consist of such processes as ablation, adsorption, and diffusion that remove existing or bring new elements from and to the system.

\subsection{Where?}

The question "where" defines the significance, which is related to the scale of the problem that may be clearly recognized on either macroscopic, or microscopic, or nano level as surface colour, reflectivity, texture, integrity, homogeneity, etc. "Solid surface" is not merely an interface between the body and the outside world, but rather a complex layered system [18], whose behaviour is altered depending on what layers are involved in the processes of energy dissipation. Hence, a distinction in the scale of surface damage can be used as a third classifying criterion.

Reviewing the scale of surface damage, we can recognise the following two types. (1) Normal state, which is characterized by localization of damage within the outer (protective) surface layers due to the dynamic equilibrium between the processes of surface destruction and formation of secondary surface films driven by chemical reaction with active environmental elements. (2) Pathological state, which is characterized by insufficient regeneration of disrupted protective surface layers, resulting in that the "relative motion between that surface and a contacting substance or substances" is accommodated within the deeper (bulk) layers and the basis material is torn [19]. 


\section{Classification}

Now, having three independent groups of answers to the above classifying questions, we define a 3-D space described by 5 types of relative motion, 4 mechanisms of surface disturbance, and 2 surface states (Fig. 1) and will fill this space with the known wear types. Obviously, different wear types can be superimposed, so, in order to map them unambiguously, certain simplification is inevitable. To this end, here we will use the approach based on dominant and accompanying processes [10], the essence of which is as follows. Depending on loading conditions, environment and materials involved, different mechanical, physical and chemical processes may take place simultaneously on friction surfaces [20]. The processes that have the greatest impact on friction and surface damage are called dominant. Together with dominant processes there are accompanying processes, whose effect on friction and wear can be neglected to a first approximation. Clearly, changes in working conditions may lead to transition from one dominant process to another. In developing this classification, only the dominant processes with no regard to their determining conditions will be considered.

Let us start with (1) Tribo-chemical wear. As follows from its name, this type of wear combines two processes, namely, the reaction with chemically active environmental elements, with oxygen being the most

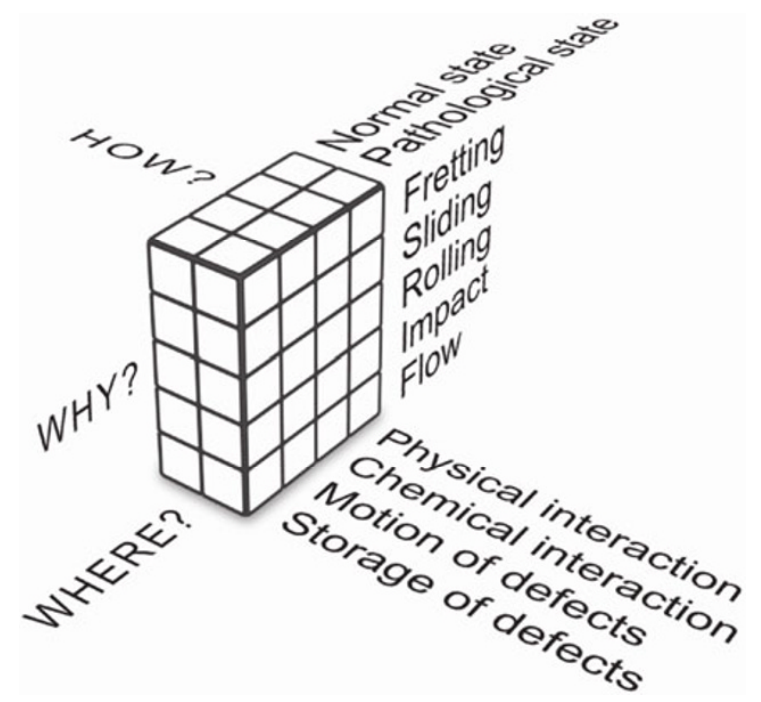

Fig. 13 -D classification space defined by 5 types of relative motion, 4 mechanisms of surface disturbance and 2 surface states. common example, and the tribological interaction between the "surface and a contacting substance or substances" that removes the reaction products from that surface. Interestingly, the latter process bears the name of the most broadly defined sense, as any interaction taking place in a contact can be called tribological. Indeed, though speaking about the same type of wear, different authors [5, 10, 11, 21-23] indicate different modes of surface destruction, mentioning fatigue, abrasion, adhesion, erosion, melting, and plastic deformation as possible mechanisms. This means that tribo-chemical wear is not limited to any particular mechanism of surface destruction, but can be run by every one of them. It can be interpreted in such a way that if the wear process is localized within the chemically formed secondary surface structures capable of continuous self-regeneration, such as oxides, for instance, the actual reason and mechanism of surface destruction are much less important. Only if the basis material below the secondary structures is torn, the surface degrades to the pathological state and there is a need to find out what mechanism is responsible for the damage. Along this line of thought, we will put the tribo-chemical wear into the abovedefined $5 \times 4 \times 2$ wear space in that way it occupies the whole $5 \times 4$ slice of the normal surface state (Fig. 2). Though this broad definition may seem not having enough resolving power or much less likely to satisfy, for instance, fretting damage, still and all, it looks consistent and leaves space for future refinements.

Left with the $5 \times 4$ slice of the pathological surface state, we will fill the vacant places by arranging the remaining wear types as shown in Fig. 3. There are eleven additional wear types to be categorized, with some of them being further subdivided into smaller subgroups.

(2) Fretting fatigue and (3) Fretting wear, which appear in fretting, originate from vibration or temperature changes in a nominally motionless contact. Damaged surfaces exhibit no signs of sliding direction, large amounts of powder oxide debris coloured differently than usual rust, and fatigue cracks initiated in fretted area [24]. These two types of damage commonly coexist, though, usually depending on operating fretting regime (partial or gross slip), one of them always dominates [25]. If fretting fatigue is the dominant form of damage, 


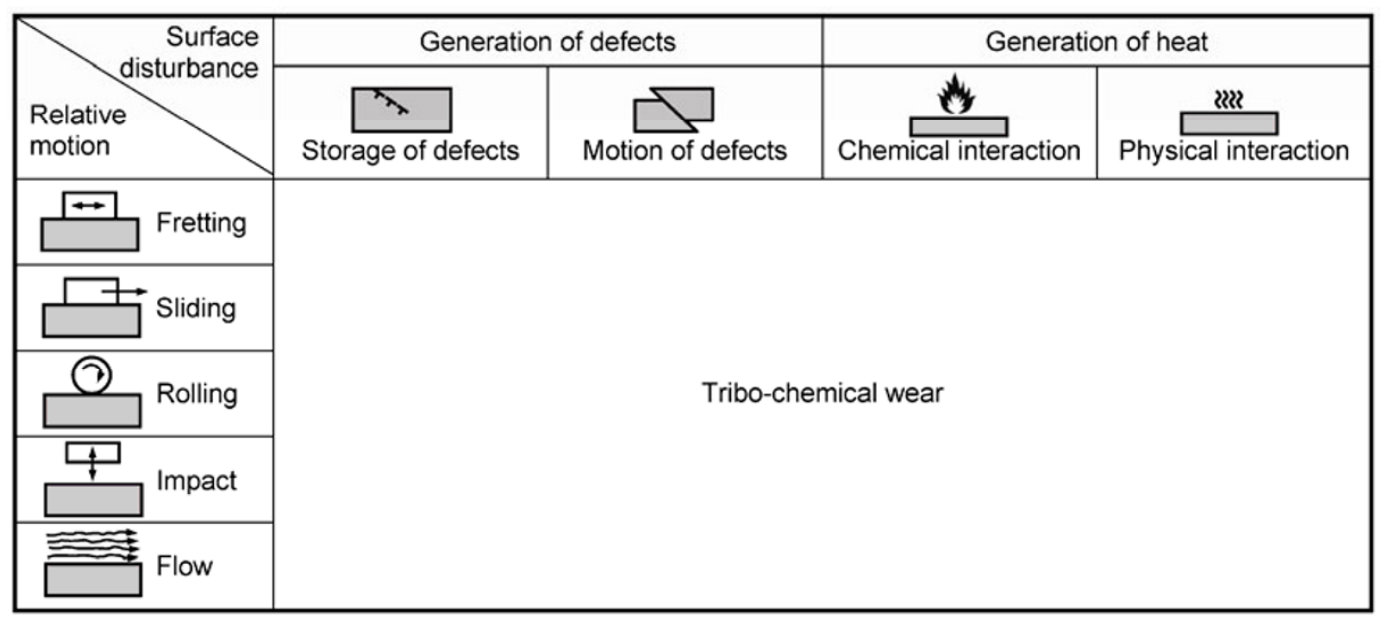

Fig. 2 Normal wear determined by localization of damage within the self-regenerating secondary protective layers.

\begin{tabular}{|c|c|c|c|c|}
\hline Surface & Generati & f defects & Generati & $n$ of heat \\
\hline $\begin{array}{l}\text { Relative } \\
\text { motion }\end{array}$ & $\left.\right|_{\text {Storage of defects }} ^{\lambda_{\lambda}}$ & Motion of defects & Chemical interaction & 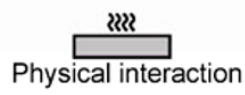 \\
\hline$\leftrightarrow$ Fretting & Fretting fatigue & \multicolumn{3}{|c|}{ Fretting wear } \\
\hline $\overrightarrow{7}$ Sliding & Fatigue wear & \multicolumn{2}{|c|}{ Abrasive wear } & \\
\hline () & Pitting & \multirow{2}{*}{\multicolumn{2}{|c|}{ Solid-particle crushing }} & Adhesive wear \\
\hline 4 Impact & Impact wear & & & \\
\hline 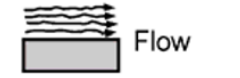 & $\begin{array}{l}\text { Liquid-impact } \\
\text { erosion }\end{array}$ & Solid-pa & le erosion & Ablation erosion \\
\hline
\end{tabular}

Fig. 3 Pathological wear types determined by relative motion and surface disturbance.

then the main mechanism of surface disturbance is the storage of defects. If fretting wear is the dominant form of damage, then the other three mechanisms of surface disturbance act simultaneously promoting each other. Interestingly, depending on loading conditions and materials involved, different mechanisms may become more pronounced, which reflects in different surface behaviour [26].

(4) Fatigue wear, (5) Pitting and (6) Impact wear, which appear in sliding, rolling, and impact, respectively, result in abrupt surface destruction due to sub-surface cracks propagated by stress cycling [5, 27, 28]. Damaged surfaces exhibit shallow or deep craters (pits) with sharp walls. Obviously, we will associate these types of wear with the storage of defects as the main mechanism of surface disturbance.
(7) Abrasive wear, which appears in sliding, results from scratching by hard particles trapped by or protuberances projecting from the mating surface and is characterized by the presence of parallel scratches in the sliding direction. Interestingly, only a very small fraction of the contacting particles or protuberances may contribute to pure mechanical chip cutting $[29,30]$, while the rest is only capable of deforming the surface. Deformation results in generation of numerous defects providing passageways for easy diffusion of active atoms, such as oxygen, into the lower surface layers, which change their mechanical properties due to chemical reactions further accelerated by heating. It is known, for instance, that abrasive wear of metals decreases significantly if oxygen is removed from the surface environment [31]. Thus, 
it seems that not only the direct cutting but also the ploughing action may contribute to the surface destruction if due to increased chemical activity of the surface the width of the brittle outer layers becomes larger. Hence, in light of the above, we will associate abrasive wear with two simultaneously acting mechanisms of surface disturbance, namely, motion of defects and chemical interaction. Abrasive wear can also be further subdivided into 2- and 3-body abrasion, with larger relative contribution of the chemical interaction mechanism in the latter case.

(8) Solid-particle crushing, which appears in rolling or impact, results from indentation of hard particles trapped between the contacting surfaces and is characterized by the presence of dent cavities of random orientation. This type of damage is also referred to as impact-abrasion $[5,32]$. Similar to abrasive wear, hard particles deform and activate the surface, which leads to formation of brittle secondary structures of significantly increased width and their subsequent destruction by other particles. It was found, for instance, that the presence of solid particles in lubricated rolling has led to about $60 \%$ less wear when the tests were performed in argon and about $40 \%$ less wear when anti-oxidant additive was used [33]. This allows us to associate solid-particle crushing with motion of defects and chemical interaction as well.

(9) Adhesive wear, which appears mainly in sliding, but can also be present in rolling and impact, results from solid-state welding of contacting surfaces and subsequent destruction of the junctions formed [34, 35]. Damaged surfaces exhibit clear signs of material transfer. Based on that the tendency of contacting surfaces to adhere arises from the attractive forces between the surface atoms of the two materials, we will associate this type of wear with the physical interaction as the main mechanism of surface disturbance.

(10) Liquid-impact erosion, which appears in flow, results from repeated impacts induced by liquid droplets impinging the surface or liquid jets hitting the surface due to the near-surface collapse of vapor bubbles. The former process is known by the name of liquid-droplet erosion and the latter process is known by the name of cavitation erosion [5], with the latter being further subdivided into hydrodynamic and vibratory cavitation erosion [36]. Worn surfaces exhibit deep pits that are often getting larger towards the inside. Liquid-impact erosion is associated with cyclic deformation, making it a fatigue-based process, which allows us to connect it to the storage of defects as the main mechanism of surface disturbance.

(11) Solid-particle erosion, which appears in flow, results from ploughing or cutting by hard particles entrained in a flowing liquid or gas and is characterized by the presence of random impact sites with raised crater rims. In contrast to 3-body abrasive wear, where the volume of the worn material depends on the normal load and the sliding distance in solid-particle erosion, the wear volume depends on the mass of particles and the velocity at which they strike the surface [37]. Similar to abrasive wear and solid-particle crushing, chemical processes accelerated by mechanical activation also play an important role in solid-particle erosion. For example, it was demonstrated that, on one hand, the oxidation rates under erosion conditions are dramatically higher than static oxidation rates [38], while, on the other hand, the erosion rate is higher under conditions of larger thickness of the oxide scale [39]. This allows us to associate solid-particle erosion with motion of defects and chemical interaction as well.

(12) Ablation erosion, which appears in flow, results from the heating of a surface induced by high-speed passage of gas or electric discharges. These processes are known by the names of gas erosion [40] and spark erosion [41], respectively. Worn surfaces exhibit random depressions and channels with scalloped edges. Clearly, we will associate this type of wear with physical interaction as the main mechanism of surface disturbance.

\section{Discussion}

The suggested classification scheme seems to harmonize the wear processes, while covering the whole field without leaving any wear type outside, which creates a coherent view of the problem. Another question is whether the system can also be used in engineering practice to guide wear mitigation. And the answer is yes. However, its use is not in determining the wear types that can be identified based on analysis 
of contact conditions, examination of damaged surface and/or studies of wear debris, but rather in recognizing the mechanisms of surface disturbance, which have to be fought in order to solve for wear problems.

As a famous example, we can discuss adhesive and abrasive wear in the presence of lubrication or even humid air, which are long known to reduce the former [34] and increase the latter [42] when much reactive fluid is used (e.g., water is replaced with oil) or just as a result of increase in humidity. The more reactive is the environment, the thicker are the secondary surface layers. In the case of adhesive wear, where physical interaction is the main mechanism of surface disturbance, thicker passive secondary structures separate better between active bulk layers and, hence, reduce the interaction leading to lower wear. In the case of abrasive wear, where motion of defects and chemical interaction are the main mechanisms of surface disturbance, both thicker and thinner secondary structure patches may be fractured and removed in a single contacting event due to their brittleness and/or stress concentration at the boundary. However, the wear rate will be obviously larger in the former case, as more material is removed at once. The base material exposed after the fracture event is, of course, modified chemically immediately to enable further surface destruction.

To summarize, it is worth adding that though the suggested approach may look oversimplified when talking about such complex phenomena as wear and do not refer to subtleties observed at the nanoscale during the last decade, it seems to provide convenient and simple order into the diversity of wear processes and build a consistent general picture, which may facilitate understanding of surface evolution during tribological interactions. As such, it can only delineate each of the known wear types without going into the depth of underlying processes or giving detailed examples. I hope that the reader will find the ideas presented here useful, and more elaborated and detailed classification will come.

\section{Conclusions}

(1) A general unifying approach to classification of wear is suggested based on information-gathering interrogative words "why", "how" and "where".

(2) A concept of surface disturbance mechanisms suitable for description of various wear types is suggested based on analysis of wear-related energy losses.

(3) Known wear types seem to fit the suggested scheme.

(4) The scheme can be useful in engineering practice to guide wear mitigation initiatives.

\section{Acknowledgements}

I thank Grigory Halperin, Izhak Etsion, and Yuri Kligerman for helpful discussion.

Open Access: This article is distributed under the terms of the Creative Commons Attribution License which permits any use, distribution, and reproduction in any medium, provided the original author(s) and source are credited.

\section{References}

[1] Mayr E, Bock W J. Classifications and other ordering systems. J Zool Syst Evol Res 40: 169-194 (2002)

[2] Archard J F. Wear theory and mechanisms. In Wear Control Handbook. New York: ASME, 1980: 35-80.

[3] Reti L, Ed. The Unknown Leonardo. New York: McGraw-Hill, 1974.

[4] Czichos H. In Tribology: A System Approach to the Science and Technology of Friction, Lubrication and Wear. New York: Elsevier, 1978: 6-8.

[5] Gates J D, Gore G J. Wear of metals: philosophies and practicalities. Mater Forum 19: 53-89 (1995)

[6] Hutchings I M. The challenge of wear. In Wear: Materials, Mechanisms and Practice. New York: John Wiley \& Sons, 2005: 1-7.

[7] Rabinowicz E. In Friction and Wear of Materials. New York: John Wiley \& Sons, 1965: 109-111.

[8] Archard J F, Hirst W. The wear of metals under unlubricated conditions. Proc Roy Soc A 236: 397-410 (1956)

[9] Burwell J T. Survey of possible wear mechanisms. Wear 1: 119-141 (1957)

[10] Kostetskii B I, Nosovskii I G, Karaulov A K, Bershadskii L I, Kostetskaya N B, Lyashko V A, Sagach M F. In The Surface Strength of Materials in Friction (in Russian). Kiev: Tekhnika, 1976: 36. 
[11] Kostetskii B I. Structure and surface strength of materials in friction. Strength of Materials 13: 359-368 (1981)

[12] Czichos H. In Tribology: A System Approach to the Science and Technology of Friction, Lubrication and Wear. New York: Elsevier, 1978: 97-104.

[13] Lim S C, Ashby M F. Wear-mechanism maps. Acta Metall 35: 1-24 (1987)

[14] Standard terminology relating to wear and erosion. ASTM G40-01, 2001.

[15] Varenberg M, Etsion I, Halperin G. Slip index: a new unified approach to fretting. Tribol Lett 17: 569-573 (2004)

[16] Courtney-Pratt J S, Eisner E. The effect of a tangential force on the contact of metallic bodies. Proc Roy Soc A 238: 529550 (1957)

[17] Czichos H. In Tribology: A System Approach to the Science and Technology of Friction, Lubrication and Wear. New York: Elsevier, 1978: 87-97.

[18] Rabinowicz E. In Friction and Wear of Materials. New York: John Wiley \& Sons, 1965: 71.

[19] Kostetskii B I, Nosovskii I G, Karaulov A K, Bershadskii L I, Kostetskaya N B, Lyashko V A, Sagach M F. In The Surface Strength of Materials in Friction (in Russian). Kiev: Tekhnika, 1976: 68-73.

[20] Holmberg K, Laukkanen A. Wear models. In Handbook of Lubrication and Tribology, Volume II. Boca Raton: CRC Press, 2012: 1-21.

[21] Czichos H. In Tribology: a System Approach to the Science and Technology of Friction, Lubrication and Wear. New York: Elsevier, 1978: 123-126.

[22] Kato K. Classification of wear mechanisms/models. In Wear: Materials, Mechanisms and Practice. New York: John Wiley \& Sons, 2005: 9-20.

[23] Mate C M. In Tribology on the Small Scale: A Bottom up Approach to Friction, Lubrication and Wear. New York: Oxford, 2008: 325-326.

[24] Waterhouse R B. In Fretting Corrosion. Oxford: Pergamon, 1972: 5 .

[25] Vingsbo O, Soderberg S. On fretting maps. Wear 126: 131147 (1988)

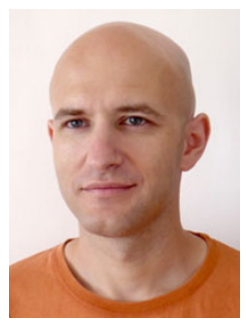

Michael VARENBERG. He received his $\mathrm{PhD}$ degree in 2004 from Technion - Israel Institute of Technology. In 2007 he joined the Department of Mechanical Engineering at Technion,
[26] Varenberg M, Halperin G, Etsion I. Different aspects of the role of wear debris in fretting wear. Wear 252: 902-910 (2002)

[27] Rabinowicz E. In Friction and Wear of Materials. New York: John Wiley \& Sons, 1965: 190-194.

[28] Czichos H. In Tribology: A System Approach to the Science and Technology of Friction, Lubrication and Wear. New York: Elsevier, 1978: 105-112.

[29] Mulhearn T O, Samuels L E. The abrasion of metals: a model of the process. Wear 5: 478-498 (1962)

[30] Tenenbaum M M. Resistance to Abrasive Wear (in Russian). Moscow: Mashinostroenie, 1976: 73-76.

[31] Hutchings I M. In Tribology: Friction and Wear of Engineering Materials. Oxford: Butterworth-Heinemann, 1992: 164-166.

[32] Khruschov M M. Principles of abrasive wear. Wear 28: 69-88 (1974)

[33] Galperin [Halperin] G L. Study of ball-bearing lifespan in field-engine driveline (in Russian). $\mathrm{PhD}$ dissertation, Saratov State Agrarian University, 1971: 12-21.

[34] Rabinowicz E. In Friction and Wear of Materials. New York: John Wiley \& Sons, 1965: 125-166.

[35] Czichos H. In Tribology: A System Approach to the Science and Technology of Friction, Lubrication and Wear. New York: Elsevier, 1978: 119-123.

[36] Garkunov D N. Tribotechnology (in Russian). Moscow: Mashinostroenie, 1985: 188-192.

[37] Hutchings I M. In Tribology: Friction and Wear of Engineering Materials. Oxford: Butterworth-Heinemann, 1992: 171-197.

[38] Sundararajan G, Roy M. Solid particle erosion behaviour of metallic materials at room and elevated temperatures. Tribol Int 30: 339-359 (1997)

[39] Roy M, Ray K K, Sundararajan G. An analysis of the transition from metal erosion to oxide erosion. Wear 217: 312-320 (1998)

[40] Chiang K T. Hot gas erosion resistance of a vapor-deposited $\mathrm{Cu}-\mathrm{Cr}$ coating. Surf Coat Tech 114: 1-6 (1999)

[41] Wang B J, Saka N. Spark erosion behavior of silver-based particulate composites. Wear 195: 133-147 (1996)

[42] Rabinowicz E. In Friction and Wear of Materials. New York: John Wiley \& Sons, 1965: 179-180.

where he is currently an assistant professor and the head of Shamban \& Microsystems Tribology Labs. His research interests are in friction and wear of engineering surfaces, micro/nano tribology, bionic tribology, tribological instrumentation, and contact mechanics. 